\title{
ATP Hydrolysis Determines Cold Tolerance by Regulating Available Energy for Glutathione Synthesis in Rice Seedling Plants
}

Pinghui $\mathrm{Yu}^{\dagger}$, Ning Jiang ${ }^{\dagger}$, Weimeng Fu, Guangjie Zheng, Guangyan Li, Baohua Feng, Tingting Chen, Jiaying Ma, Hubo Li, Longxing Tao* and Guanfu Fu*

\begin{abstract}
Background: Glutathione (GSH) is important for plants to resist abiotic stress, and a large amount of energy is required in the process. However, it is not clear how the energy status affects the accumulation of GSH in plants under cold stress.

Results: Two rice pure lines, Zhongzao39 (ZZ39) and its recombinant inbred line 82 (RIL82) were subjected to cold stress for $48 \mathrm{~h}$. Under cold stress, RIL82 suffered more damages than ZZ39 plants, in which higher increases in APX activity and GSH content were showed in the latter than the former compared with their respective controls. This indicated that GSH was mainly responsible for the different cold tolerance between these two rice plants. Interestingly, under cold stress, greater increases in contents of carbohydrate, NAD(H), NADP(H) and ATP as well as the expression levels of GSH1 and GSH2 were showed in RIL82 than ZZ39 plants. In contrast, ATPase content in RIL82 plants was adversely inhibited by cold stress while it increased significantly in ZZ39 plants. This indicated that cold stress reduced the accumulation of GSH in RIL82 plants mainly due to the inhibition on ATP hydrolysis rather than energy deficit.

Conclusion: We inferred that the energy status determined by ATP hydrolysis involved in regulating the cold tolerance of plants by controlling GSH synthesis.
\end{abstract}

Keywords: ATP hydrolysis, Antioxidation, Cold stress, Energy status, Glutathione, Oryza sativa

\section{Background}

Rice is one of the most important crops in the world (Seck et al. 2012; Chauhan et al. 2017). It plays an important role in Asian grain production, which has made a great contribution to food security (Aryal and Kandel 2017; Chauhan et al. 2017; Rahaman and Shehab 2019). As a typical subtropical or tropical crop, rice plants are always damaged by cold sress (Zhao et al. 2015; Wu et al. 2016; Chen et al. 2017). This stress is not only detrimental to plant growth and development ( $\mathrm{Su}$ et al. 2010; Thomashow 2010; Kim

\footnotetext{
* Correspondence: taolongxing@caas.cn; fugf1981@sina.com

'Pinghui Yu and Ning Jiang contributed equally to this work.

National Key Laboratory of Rice Biology, China National Rice Research Institute, Hangzhou 310006, China
}

\section{Springer Open}

et al. 2017), but also limits spatial distribution and grain productivity (Su et al. 2010; Wang et al. 2016; Uphoff and Thakur 2019). It has been reported that cold stress occurring at reproductive phase can result in a large reduction in grain yield (Thakur et al. 2010; Ghadirnezhad and Fallah 2014). Additionally, slow seedling development, yellowing, withering, reduced tillering and stunted growth are always observed under cold stress at the seedling stage (Su et al. 2010; Bonnecarrère et al. 2011; Han et al. 2017; Cong Dien and Yamakawa 2019). As a result, the cultivated area of early rice and double-season late rice is significantly reduced in China (Sun and Huang 2011; Yu et al. 2012; Wang et al. 2019).

(c) The Author(s). 2020 Open Access This article is licensed under a Creative Commons Attribution 4.0 International License which permits use, sharing, adaptation, distribution and reproduction in any medium or format, as long as you give appropriate credit to the original author(s) and the source, provide a link to the Creative Commons licence, and indicate if changes were made. The images or other third party material in this article are included in the article's Creative Commons licence, unless indicated otherwise in a credit line to the material. If material is not included in the article's Creative Commons licence and your intended use is not permitted by statutory regulation or exceeds the permitted use, you will need to obtain permission directly from the copyright holder. To view a copy of this licence, visit http://creativecommons.org/licenses/by/4.0/. 
Cold stress can directly inhibit the metabolic reaction of plants and induce osmotic, oxidative and other stresses, thus preventing the expression of all genetic potential (Chinnusamy et al. 2007; Kazemi-Shahandashti and MaaliAmiri 2018; Shi et al. 2018). Indeed, the degree of damage to rice plants usually depends on time of occurrence (growth phase), the severity of chilling, and the duration of the cold stress (Li et al. 1981; Ye et al. 2009). It has been reported that the chilling threshold temperature in the early stages of development (germination and vegetative growth) is low $\left(10-13^{\circ} \mathrm{C}\right)$, while during the reproductive stage, the threshold temperature of rice is high $\left(18-20^{\circ} \mathrm{C}\right)$ (Yoshida 1981; Ghadirnezhad and Fallah 2014). During this process, cold stress causes multiple dysfunctions at the cellular level, including membrane damage, ROS production, protein denaturation and accumulation of toxic products (Bowers 1994). As a result, many tropical or subtropical crops are damaged or killed and exhibit the symptoms of chlorosis, necrosis, or growth retardation (McDonald 2002; Sanghera et al. 2011). It is worth noting that cold-tolerant species can grow at very low temperature (Sanghera et al. 2011; Xu and Cai 2014; Liu et al. 2019). Cold acclimation has been reported to be associated with a variety of mechanisms such as gene expression, change of membrane composition, accumulation of cryoprotectants and elevation of phytohormones (Lang et al. 1994; Yadav 2010; Chen et al. 2019). Among these changes, the enhancement of antioxidant capacity, especially the glutathione (GSH), is one of the most important factors for rice plants to resist cold stress since the plants cannot survive without glutathione $(\gamma$-glutamylcysteinylglycine) or $\gamma$-glutamylcysteine containing homologues (Tausz et al. 2004; Noctor et al. 2012; Hausladen and Alscher 2017; Banerjee and Roychoudhury 2019).

The GSH is the most abundant form of organic sulphur in plants apart from that incorporated into proteins, and it predominantly presents in its reduced form (GSH), with only a small proportion present in its fully oxidised state (GSSG) (Rao and Reddy 2008; Noctor et al. 2012). Indeed, GSH is an essential metabolite with a variety of functions found in plants, such as the biosynthetic pathways, detoxification, antioxidant biochemistry and redox homeostasis (Rao and Reddy 2008; Noctor et al. 2012). The most fundamental and earliest function of glutathione is in the thiol-disulphide interaction, in which reduced glutathione (GSH) is continuously oxidized to the disulphide bond form (GSSG) that is recycled to GSH by NADPH-dependent glutathione reductase (GR) (Belorgey et al. 2013; Csiszár et al. 2016). Importantly, the function of GSH in plant development cannot be achieved by other thiols or antioxidants (Noctor et al. 2012). As an important component of the ascorbate-glutathione (AsA-GSH) cycle which consists of two dominating nonenzymatic antioxidants, GSH andAsA, and four enzymes [ascorbate peroxidase (APX), monodehydroascorbate reductase (MDHAR), dehydroascorbate reductase (DHAR) and GR], GSH is involved in the removal of hydrogen peroxide caused by cold stress (O'Kane et al. 1996; Noctor and Foyer 1998; Noctor et al. 1998). In the process of hardening, the accumulation of GSH and the ratio of glutathione reduced/oxidized as parts of a complex regulatory function enhance the frost resistance of wheat (Kocsy et al. 2000; Galiba et al. 2001; Hausladen and Alscher 2017). Similarly, the enhancement of ratios of reduced and oxidized forms of AsA (AsA/ DHA) and GSH (GSH/GSSG), and the fluctuation of activities of APX, GR, and DHAR in melon seedlings are induced by melatonin under cold stress (Zhang et al. 2017). Additionally, GSH and AsA were reported to be interacted with $\mathrm{H}_{2} \mathrm{O}_{2}$ signaling to enhance the antioxidant capacity of tomato under cold stress (Liu et al. 2018). Indeed, GSH is also resistant to cold stress through other pathways, including redox signaling, secondary metabolism and xenobiotic detoxification (Noctor et al. 2012). These processes are high-energy cost, in which the ATP, $\operatorname{NAD}(H)$ and $\mathrm{NADP}(\mathrm{H})$ are involved. However, few studies have investigated the relationship between GSH metabolism and energy status in plants under cold stress, and the underlying mechanism remains unclear.

Many studies have shown that $\gamma$-glutamylcysteine synthetase ( $\gamma$-ECS) and glutathione synthetase (GSH-S) play important roles in GSH synthesis in plants (Cairns et al. 2006; Pasternak et al. 2008). However, both pathways are ATP-dependent (Rennenberg 1980; Meister 1988; Mullineaux and Rausch 2005) that the synthesis of GSH is affected by the energy status in plants. Moreover, the accumulation of GSH can be regulated by GR, which can resist oxidative stress caused by cold, drought, and high light and salinity (Rao and Reddy 2008). It is worth noting that GR used NADPH as an electron donor to reduce GSSG to GSH (Rao and Reddy 2008; Noctor et al. 2012). In fact, GR utilizes NADH to catalyze the reduction of GSSG with low efficiency (Halliwell and Foyer 1978). These results suggest that the role of GSH in plants against cold stress is a high energy-consuming process. However, energy shortage is always found in plants under abiotic stress, which may impair the antioxidant capacity, especially for low resistant plants (BaenaGonzález and Sheen 2008; Jin et al. 2015; Dahal and Vanlerberghe 2017; Asami et al. 2018; Islam et al. 2019). Therefore, energy homeostasis is critical for plants to survive in abiotic stresses, including cold stress, by accumulating GSH. In our study, two rice pure lines with different cold tolerance were selected to investigate how energy status affects the accumulation of GSH in plants, in which the antioxidant capacity, carbohydrate metabolism, GSH and energy, heat shock proteins, relative electrical conductance (REC), maximum fluorescence quantum efficiency ( $\mathrm{Fv} / \mathrm{Fm})$ and actual fluorescence quantum efficiency (Y (II)) of leaves were determined. 


\section{Methods}

\section{Plant Materials and Growth Conditions}

This study was conducted at an experimental farm at the National Rice Research Institute in Hangzhou, Zhejiang Province, China. Two rice pure lines were selected, namely Zhongzao39 (ZZ39, cold tolerant) and its recombinant inbred line 82 (RIL82, cold susceptible), which is a F9 line that was selected from the RIL population derived from the rice cross ZZ39 $\times$ ZJZ17 (Zhongjiazao17). The rice seeds were soaked for $48 \mathrm{~h}$, germinated at $37^{\circ} \mathrm{C}$ for $24 \mathrm{~h}$, and then were sown directly in the pots $(10 \mathrm{~cm}$ height and $10 \mathrm{~cm}$ diameter) in a plant growth chamber where the air temperature was controlled at $28 / 22^{\circ} \mathrm{C}$ (day/night), the relative humidity was $70 \%$ under the natural sunlight of $1000 \mu \mathrm{mol} \mathrm{m} \mathrm{m}^{-2} \mathrm{~s}^{-1}$. At the six-leaf stage, two rice pure lines were subjected to cold stress for $48 \mathrm{~h}$, where the stress temperature were set to be $13 / 10^{\circ} \mathrm{C}$ (day/night), while the control temperature was $25 / 20^{\circ} \mathrm{C}$ (day/night). During the period, the relative humidity was maintained at $70 \%$ and the light intensity was $300 \mu \mathrm{mol} \mathrm{m} \mathrm{m}^{-2} \mathrm{~s}^{-1}$. At the end of cold stress, the first fully expanded leaves were selected to determine the Fv/Fm and Y (II), and then collected to determine the REC, MDA, $\mathrm{H}_{2} \mathrm{O}_{2}$, chlorophyll, carbohydrates, energy metabolism and allocation, antioxidant capacity, GSH, GSH-S, GR and heat shock proteins (HSPs).

\section{Effect of Glutathione (GSH) and 3-Ab Alone or Together on Rice Plants under Cold Stress}

In order to investigate the underlying mechanism of GSH and 3 -ab functioned in cold tolerance of rice, $1 \mathrm{mmol} \cdot \mathrm{L}^{-1}$ GSH and $25 \mathrm{mmol} \cdot \mathrm{L}^{-1}$ buthionine sulfoximine (BSO, a GSH synthetic inhibitor, Noctor et al. 2012) as well as a 1 $\mathrm{mmol} \cdot \mathrm{L}^{-1}$ Poly (ADP-ribose) polymerase (PARP) synthetic inhibitor 3-aminobenzamide (3-ab, Keppler et al. 2018) containing $0.1 \%(\mathrm{v} / \mathrm{v})$ Tween 20 as a surfactant were sprayed onto rice leaves with $10 \mathrm{~mL}$ per pot about $30 \mathrm{~min}$ before cold stress conducted. The first fully expanded leaf samples were collected to determine REC and MDA $48 \mathrm{~h}$ later. According to the above results, the synergistic effects of GSH and 3-ab on cold tolerance of rice plant were also investigated. About $30 \mathrm{~min}$ before the cold stress, these two chemicals containing $0.1 \%(\mathrm{v} / \mathrm{v})$ Tween 20 as a surfactant were sprayed on rice leaves with $10 \mathrm{~mL}$ per pot together. $48 \mathrm{~h}$ later, the first fully expanded leaves were collected to determine the $\mathrm{H}_{2} \mathrm{O}_{2}, \mathrm{MDA}, \mathrm{GSH}$ and ATP levels and the contents of PARP and ATPase.

\section{Measurements of Chlorophyll Content and Fluorescence Quantum Efficiency}

The chlorophyll concentration was measured using an ethonal extraction procedure (Sartory and Grobbelaar 1984), in which $0.1 \mathrm{~g}$ leaf sample was sliced and immersed in $20 \mathrm{~mL} 95 \%$ ethanol for $48 \mathrm{~h}$ in the dark. Chlorophyll concentration was determined at $665 \mathrm{~nm}$ and $649 \mathrm{~nm}$ using a spectrophotometer (Lambda25; Perkin Elmer, Freemont, CA, USA).

After a 30-min dark adaptation period, Fv/Fm and $\mathrm{Y}$ (II) of the leaves were measured using a portable chlorophyll fluorescence spectrometer (PAM-2500 chlorophyll fluorescence system; Heinz Walz, Effeltrich, Germany) (Zhang et al. 2018a).

\section{Relative Electrical Conductance Measurement}

Following the method of Xiong et al. (2012), $0.5 \mathrm{~g}$ of fresh leaves were collected at the end of the cold stress, cut into $25-\mathrm{mm}^{2}$ pieces, and immediately immersed into a test tube with $12 \mathrm{~mL}$ deionized water for $2 \mathrm{~h}$ at $25^{\circ} \mathrm{C}$. After incubation, a conductivity meter (DDA-11A; Shanghai Hongyi Instrument Co. Ltd., Shanghai, China) was used to measure the electrical conductivity of the solution (EC1). The electrical conductivity (EC2) was measured again after the samples were heated at $80^{\circ} \mathrm{C}$ for $2 \mathrm{~h}$ in their effusates and cooled to $25^{\circ} \mathrm{C}$. The relative ion leakage was calculated as the ratio between $\mathrm{EC} 1$ and $\mathrm{EC} 2$.

\section{$\mathrm{H}_{2} \mathrm{O}_{2}$ Measurement}

Following the method of Brennan and Frenkel (1977) with some modifications, about $0.2 \mathrm{~g}$ of frozen leaves were homogenized in $4 \mathrm{~mL}$ extraction solution containing $10 \mathrm{mM}$ 3-amino-1, 2, 4-triazole. The solution was centrifuged at $6000 \times g$ for $25 \mathrm{~min}$, and then $1 \mathrm{~mL}$ of $0.1 \%$ titanium tetrachloride dissolved in $20 \% \mathrm{H}_{2} \mathrm{SO}_{4}$ was added to $2 \mathrm{~mL}$ of the supernatant. After the reaction, undissolved material was removed from the solution, the absorbance was determined at $410 \mathrm{~nm}$ by a spectrophotometer (Lambda 25; Perkin Elmer, Freemont, CA, USA).

\section{Lipid Peroxidation Measurement}

About $0.2 \mathrm{~g}$ of frozen leaves were homogenized in $2 \mathrm{~mL}$ of $5 \%$ trichloroacetic acid, and then the MDA content was estimated through determining the concentration of thiobarbituric acid reactive substances (Dhindsa et al. 1981).

\section{Antioxidant Enzyme Activity Measurements}

The superoxide dismutase (SOD) activity was determined by the method of Giannopolitis and Ries (1977). The peroxidase (POD) activity was measured by the method of Maehly and Chance (1954), in which the guaiacol was converted to tetra guaiacol, and was monitored at $470 \mathrm{~nm}$. The catalase activity (CAT) was determined using the modified method of Aebi (1974) as described by Zhang et al. (2016). The ascorbate peroxidase (APX) activity was determined by the method of Bonnecarrère et al. (2011).

Measurements of GSH and GSSG Content and GR Activity The glutathione content was assayed by monitoring the change in absorbance of 2-nitro-5-thiobenzoic acid at $412 \mathrm{~nm}$ for $5 \mathrm{~min}$ (Noctor et al. 2016). The GSSG 
content was determined by the kit from the Comin Biotechnology Co., Ltd., Suzhou, China. The GR activity was assayed by monitoring the decrease in NADPH at $340 \mathrm{~nm}$ for $3 \mathrm{~min}$ using a kit from the Beijing Solarbio Science \& Technology Co., Ltd., Beijing, China.

\section{Carbohydrate Measurements}

According to the modified anthrone-sulphuric acid colorimetric method (Dubois et al. 1956), fresh leaf samples $(0.2 \mathrm{~g})$ saturated in $10 \mathrm{ml}$ of deionized water were boiled for $20 \mathrm{~min}$ to determine the soluble sugar and starch contents. To determine soluble sugar, the extract was filtered and treated with anthrone and 98\% sulphuric acid, and the mixture was incubated in boiling water for 15 min. A spectrophotometer (Lambda25; Perkin Elmer, Freemont, CA, USA) was used to determine the absorbance at $485 \mathrm{~nm}$. As to starch content, the sediment of the filtered extract containing sugar content was dried, weighed, and boiled with deionized water and perchloric acid at $9.2 \mathrm{M}$ and $4.6 \mathrm{M}$, respectively. The supernatant was also determined by a spectrophotometer at $485 \mathrm{~nm}$. The total non-structural carbohydrate (NSC) was calculated as the sum of soluble sugar and starch contents.

\section{$\mathrm{NAD}(\mathrm{H})$ and $\mathrm{NADP}(\mathrm{H})$ Measurements}

The $\mathrm{NAD}(\mathrm{H})$ and $\operatorname{NADP}(\mathrm{H})$ were extracted with $1 \mathrm{~mL}$ $0.1 \mathrm{M} \mathrm{HCl}$ or $0.1 \mathrm{M} \mathrm{NaOH}$, respectively (Matsumura and Miyachi 1980). For $\mathrm{NAD}(\mathrm{H})$ including $\mathrm{NAD}^{+}$and
$\mathrm{NADH}$, their contents were determined by an assay kit, and another kit was used to determine the $\operatorname{NADP}(\mathrm{H})$ content according to the manufacturer's instructions (Comin Biotechnology Co., Ltd., Suzhou, China).

\section{ATP and ADP Measurements}

The ATP and ADP contents were determined using ATP and ADP assay kits according to the manufacturer's instructions (Shanghai Enzyme-linked Biotechnology Co., Ltd., China). During this process, $0.1 \mathrm{~g}$ of frozen leaves were homogenized with $1 \mathrm{~mL}$ of $0.1 \mathrm{M} \mathrm{PH7.4} \mathrm{PBS} \mathrm{in} \mathrm{an}$ ice bath and centrifuged at $3000 \times g$ for $20 \mathrm{~min}$. The supernatant was collected for analysis at $450 \mathrm{~nm}$.

\section{ATPase Content}

ATPase content was determined with by the ELISA method and an assay kit according to the manufacturer's instructions (Shanghai Enzyme-linked Biotechnology Co., Ltd., China). During this process, $0.1 \mathrm{~g}$ of frozen leaves were extracted with $0.1 \mathrm{M} \mathrm{PH7.4} \mathrm{PBS,} \mathrm{and} \mathrm{then}$ centrifuged at $3000 \times g$ for $20 \mathrm{~min}$ at $4{ }^{\circ} \mathrm{C}$. The supernatant was collected for analysis at $450 \mathrm{~nm}$.

\section{PARP Content}

PARP content was determined by ELISA method and an assay kit according to the manufacturer's instructions (Shanghai Enzyme-linked Biotechnology Co., Ltd., China). During this process, $0.2 \mathrm{~g}$ of frozen leaves were extracted
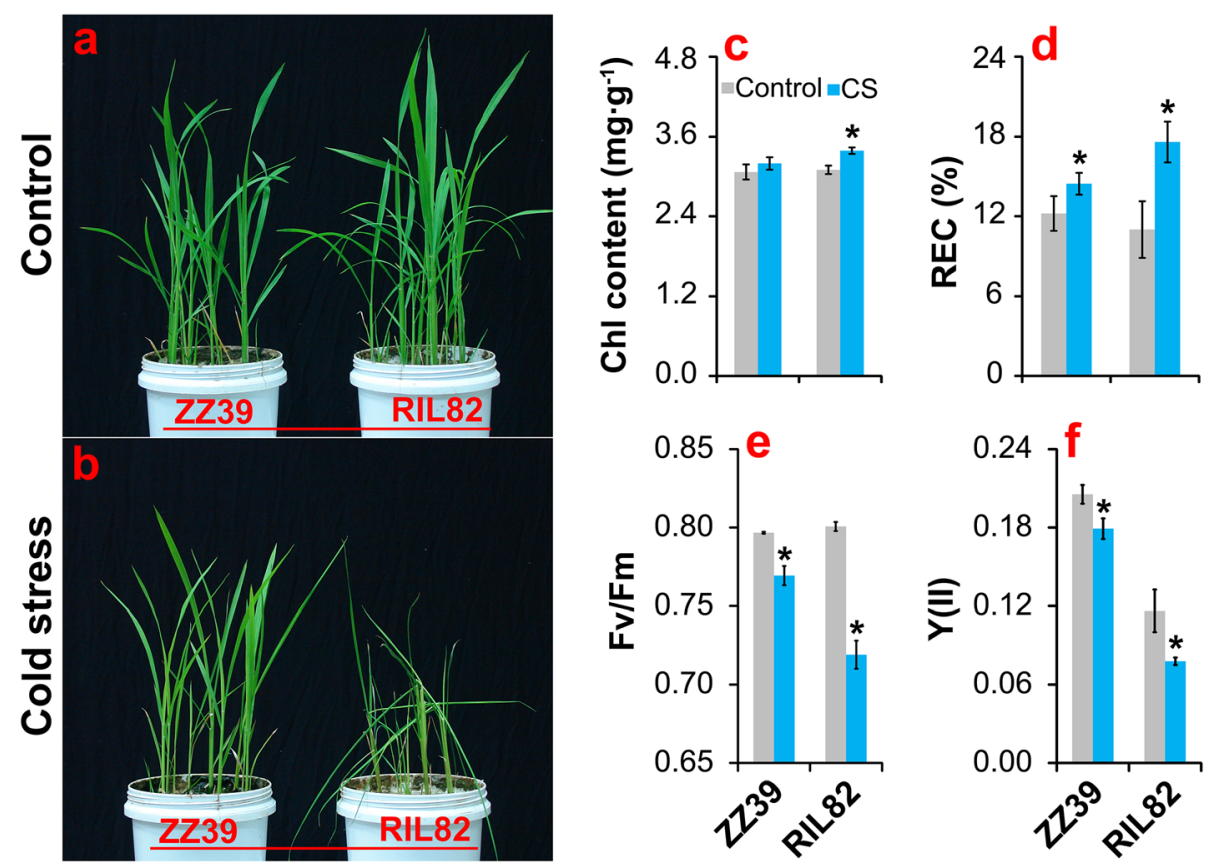

Fig. 1 The response of rice plants to cold stress. $\mathbf{a}$ and $\mathbf{b}$, The photograph of ZZ39 and RIL 82 plants under control and cold stress conditions, respectively; c, Chlorophyll content; d, REC; e, Fv/Fm; f, Y (II). Chl, Chlrophyll; REC, Relative electrical conductance; Fv/Fm, Maximum fluorescence quantum of PSII; Y (II), Actual fluorescence quantum of PSII. Vertical bars denote standard deviations $(n=4)$. A $t$-test was adopted to compare the difference between control and cold stress within a cultivar. ${ }^{*}$ denotes $P<0.05$ 
with $0.1 \mathrm{M}$ PH7.4 PBS, and then centrifuged for $20 \mathrm{~min}$ at $3000 \times g$. The supernatant was collected for analysis at 450 $\mathrm{nm}$.

\section{Quantitative Real-Time Polymerase Chain Reaction (PCR) Analysis}

Total RNA was extracted from $0.3 \mathrm{~g}$ leaves using TRIpure reagent (Aidlab Biotechnologies, Beijing, China). RNA was converted to first-strand cDNA using ReverTra Ace qPCR RT Master Mix (TOYOBO, Shanghai, China). The SYBR Green I (TOYOBO) was used as a fluorescent reporter, and the resultant cDNA was used as a template for quantitative PCR amplification in a Thermal Cycler Dice Real Time System II (TaKaRa Biotechnology, Dalian, China). Primers were designed using PRIMER5 software (Rozen and Skaletsky 2000). The primers for genes examined were listed in Supplementary Table 1 . The PCR and detection were performed as described above (Feng et al. 2013). Relative transcript levels were analyzed using $2^{-\Delta \Delta C T}$ method and the experiments were performed in triplicate.

\section{Statistical Analysis}

Data were processed using SPSS software 11.5 (IBM Corp., Armonk, NY, USA) to detect differences. The mean values and standard errors in the figures represented data from three experimental replicates unless otherwise stated. The $t$-test was performed on the normalized data. An analysis of variance (ANOVA) with two factors (temperature and treatment) was used to compare the differences in LSD test with $p(p \leq 0.05)$.

\section{Results}

Changes of Leaf Morphology, Photosynthesis and REC under Cold Stress

Rice plants ZZ39 and RIL82 showed different responses to cold stress (Fig. 1). Under control conditions, there was no difference in leaf morphology between the two rice plants. However, the leaves of RIL82 plants withered under cold stress, while the leaves of ZZ39 plants remained flat (Fig. 1a, b). The chlorophyll content of the leaves of ZZ39 plants maintained constant under cold stress, but it increased significantly in RIL82 plants compared with control (Fig. 1c).

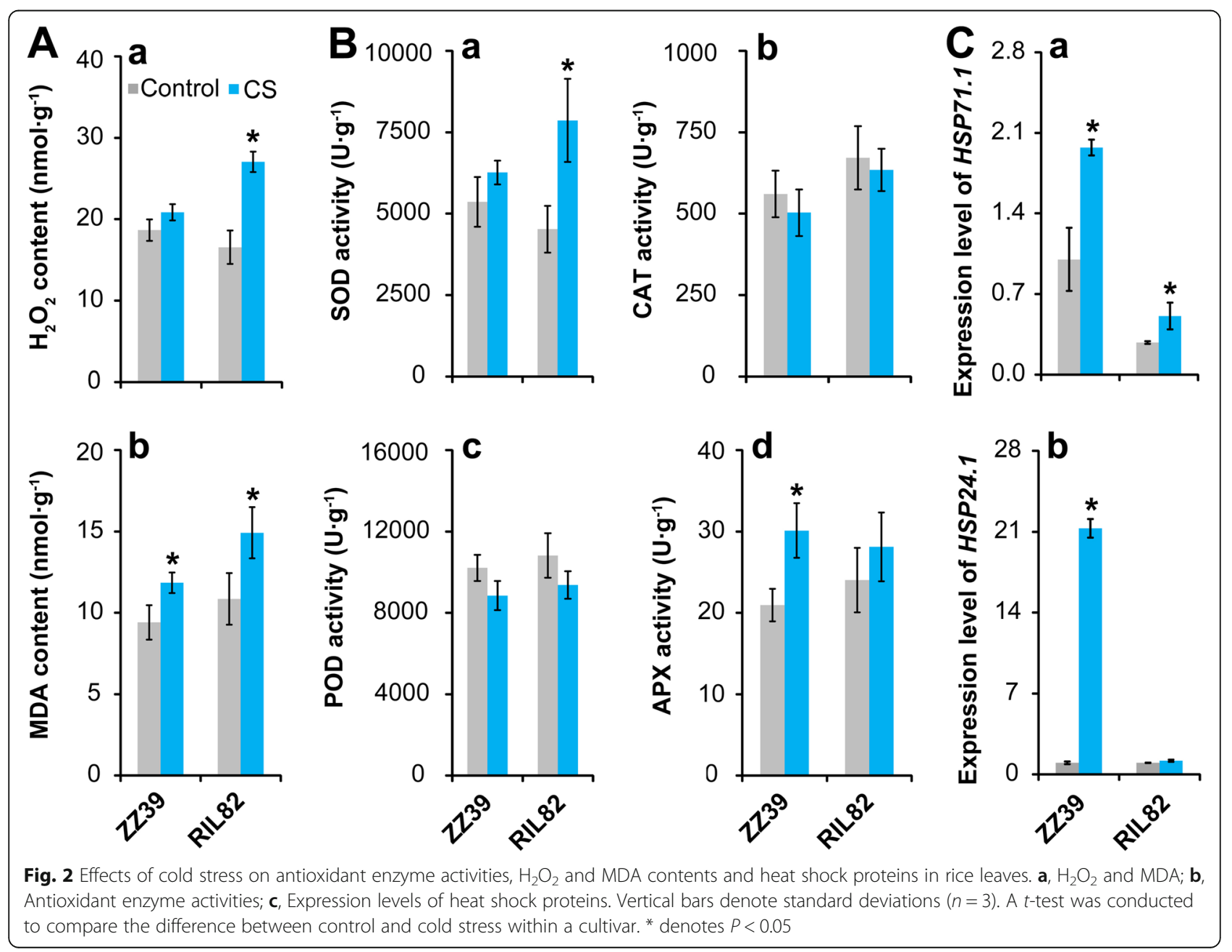


Similarly, higher increase in REC of leaf was found in RIL82 than ZZ39 plants under cold stress (Fig. 1d). In contrast, both $\mathrm{Fv} / \mathrm{Fm}$ and $\mathrm{Y}$ (II) values deceased significantly in response to cold stress, and RIL82 plants decreased more than ZZ39 plants (Fig. 1e, f).

\section{$\mathrm{H}_{2} \mathrm{O}_{2}$ and MDA Contents}

The $\mathrm{H}_{2} \mathrm{O}_{2}$ content in the leaves of $\mathrm{ZZ39}$ plants was not affected by cold stress as there was no significant difference between the control and cold stress groups (Fig. 2A, a). However, the $\mathrm{H}_{2} \mathrm{O}_{2}$ content in RIL82 plants increased significantly in response to cold stress. The MDA content of both plants increased significantly under cold stress (Fig. $2 \mathrm{~A}, \mathrm{~b})$. Compared with the control groups, a greater increase in MDA content was found in RIL82 than ZZ39 plants under cold stress.

\section{Antioxidant Enzyme Activities}

The activities of SOD, POD, CAT and APX were determined to investigate the effects of cold stress on the antioxidant capacity (Fig. 2B). No difference in SOD activity was found between the control and cold stress groups of ZZ39 plants, while a significant increase in SOD activity was observed in RIL82 plants under cold stress (Fig. 2B, a). The activities of POD and CAT were not affected by cold stress as no differences were showed between the control and cold stress groups (Fig. 2B, b and c). However, the APX activity of ZZ39 plants increased significantly under cold stress, while no significant difference was showed between the control and cold stress groups of RIL82 plants (Fig. 2B, d).

\section{Heat Shock Proteins}

The genes associated with heat shock proteins were determined, such as HSP71.1 and HSP24.1 (Fig. 2C). The expression level of HSP71.1 was significantly induced by cold stress in both rice plants, where higher increase was found in ZZ39 than RIL82 plants (Fig. 2C, a). Compared with the control, about 26-fold increase in expression level of HSP24.1 was showed in ZZ39 plants under cold stress, while no difference was found in RIL82 plants between the control and cold stress groups (Fig. 2C, b).

\section{GSH Metabolism}

According to the above results, APX was mainly responsible for reducing the $\mathrm{H}_{2} \mathrm{O}_{2}$ and MDA levels caused by cold stress, which was presumably related to GSH. Therefore, the metabolism of GSH was determined under cold stress.
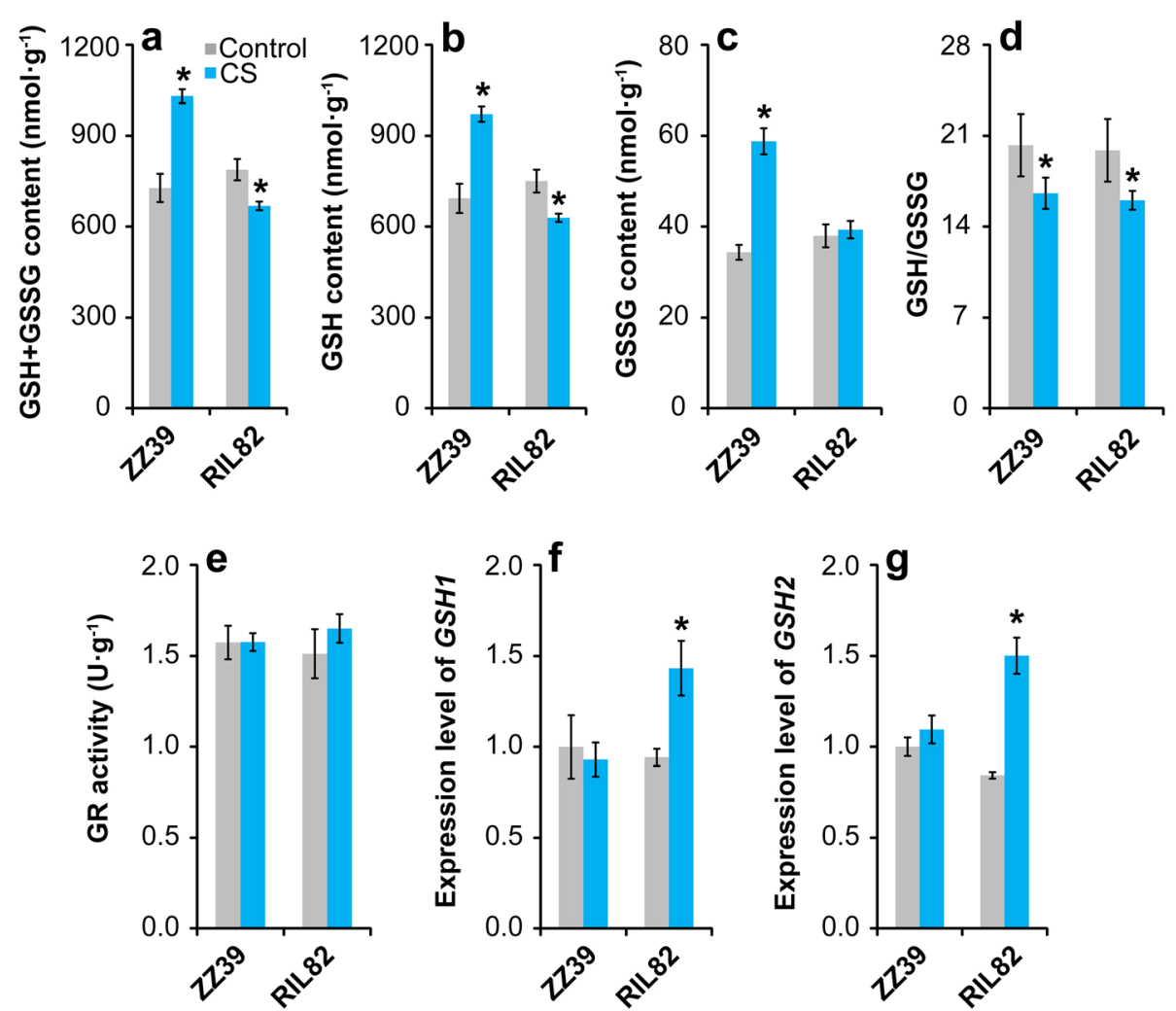

Fig. 3 Effect of cold stress on the GSH metabolism in rice leaves. a, GSH + GSSG; b, GSH; c, GSSG; d, GSSG/GSH; e, GR activity; f, GSH1; $\mathbf{g}$, GSH2. GSH, glutathione; GSSG, glutathione disulphide (Oxidant glutathione); GR, glutathione reductase. Vertical bars denote standard deviations $(n=4)$. A t-test was conducted to compare the difference between control and cold stress within a cultivar. ${ }^{*}$ denotes $P<0.05$ 
Compared with the control, the contents of GSH + GSSG, GSH, and GSSG in the leaves of ZZ39 increased significantly under cold stress, while they decreased clearly in RIL82 plants except for the GSSG (Fig. 3a-c). Regarding the GSH/GSSG, it was significantly reduced by cold stress, but no obvious difference in decrease was showed between these two rice plants (Fig. 3d). Additionally, there was no obvious difference in GR activity between the control and cold stress groups in both rice plants (Fig. 3e). Similarly, no significant differences in the expression levels of GSH1 and GSH2 of leaves in ZZ39 plants were showed between the control and cold stress groups (Fig. 3f, g), while they increased significantly in RIL82 plants under cold stress.

\section{Energy Production and Consumption}

The energy status is important for GSH accumulation in RIL82 plants under cold stress, since the process of GSH synthesis is dependent on ATP. Carbohydrates, including NSC, soluble sugars and starch are fundamental substrates for energy production such as $\mathrm{NAD}(\mathrm{H}), \mathrm{NADP}(\mathrm{H})$ and ATP, thus their contents were determined in plants under cold stress. Cold stress caused a few effect on the NSC content of ZZ39 plants, while a remarkable increase was found in RIL82 plants under cold stress compared with control (Fig. 4A, a). In response to cold stress, the soluble sugar content increased significantly in both rice plants, while higher increase was found in ZZ39 than RIL82

B
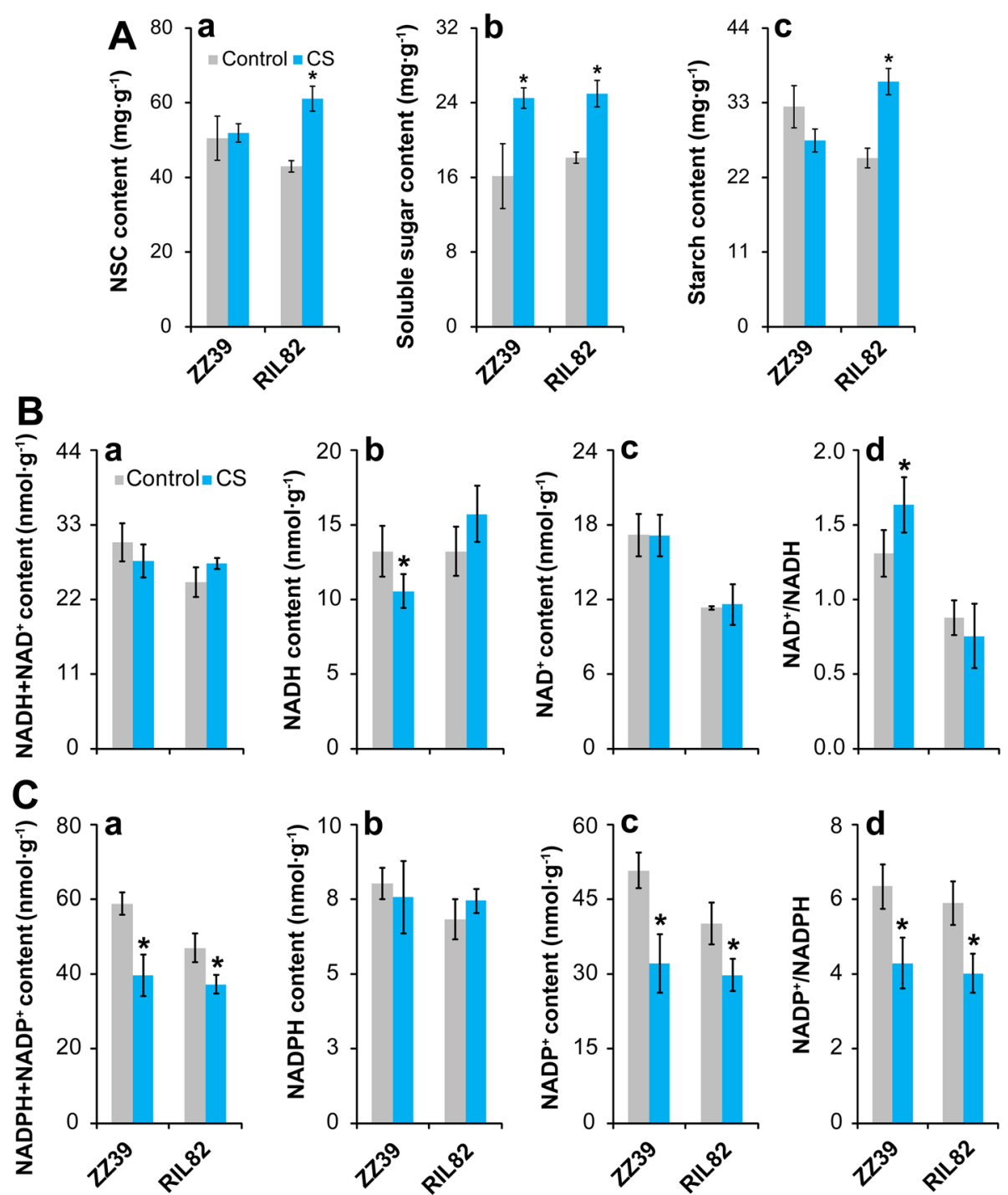

Fig. 4 Effects of cold stress on carbohydrate, $N A D(H)$ and NADP(H) contents in rice leaves. a, Carbohydrates; b, NAD(H) metabolism; $\mathbf{c}$, NADP(H) metabolism. NSC, Non-structural carbohydrates; NAD(H), Nicotinamide adenine dinucleotide; NADP $(H)$, Nicotinamide adenine dinucleotide phosphate. Vertical bars denote standard deviations $(n=4)$. A $t$-test was conducted to compare the difference between control and cold stress within a cultivar. ${ }^{*}$ denotes $P<0.05$ 
plants compared with control (Fig. 4A, b). Interestingly, the starch content in leaves of ZZ39 decreased under cold stress, while a large increase was showed in RIL82 plants (Fig. 4A, c).

Cold stress caused a few effect on the contents of $\mathrm{NAD}^{+}+\mathrm{NADH}$ and $\mathrm{NAD}^{+}$, since there were no obvious differences between the control and cold stress groups in either plants (Fig. 4B, a and c). The NADH content of ZZ39 plants significantly decreased under cold stress, while slight increase was found in RIL82 plants compared with control (Fig. 4B, b). In contrast, the $\mathrm{NAD}^{+} / \mathrm{NADH}$ increased significantly in ZZ39 plants in response to cold stress, while no obvious difference was showed between the control and cold stress group in RIL82 plants (Fig. 4B, d). As to the contents of $\mathrm{NADP}^{+}+\mathrm{NADPH}$ and $\mathrm{NADP}^{+}$as well as $\mathrm{NAD}^{+}$/ $\mathrm{NADPH}$, they decreased significantly in ZZ39 and RIL82 plants under cold stress, and higher decreases were found in the former than the latter (Fig. 4C, a, c and d). In contrast, the differences in NADPH between the control and cold stress groups were not significant in two rice plants (Fig. 4C, b).
Under cold stress, the contents of ATP + ADP, ATP and ADP in ZZ39 plants decreased compared with their respective controls. However, they increased in RIL82 plants under cold stress with significant differences showed in ATP + ADP and ATP (Fig. 5a-c). In contrast, the ADP/ATP, ATPase content and expression level of ATPase in ZZ39 plants increased clearly in response to cold stress, while a great reduction was found in RIL82 plants except for ADP/ATP (Fig. 5d-f).

\section{PARP Content and Expression Levels of Genes Associated with SnRK1 and TOR}

The PARP content of both plants significantly increased under cold stress, and higher increase was found in RIL82 than ZZ39 plants compared with control (Fig. 6a). The SnRK1A and SnRK1B genes were significantly expressed by cold stress, in which the increase in ZZ39 plants was higher than that in RIL82 plants (Fig. 6b, c). Compared with control, the expression level of TOR of ZZ39 plants increased slightly under cold stress, while a large decrease was showed in RIL82 plants (Fig. 6d).
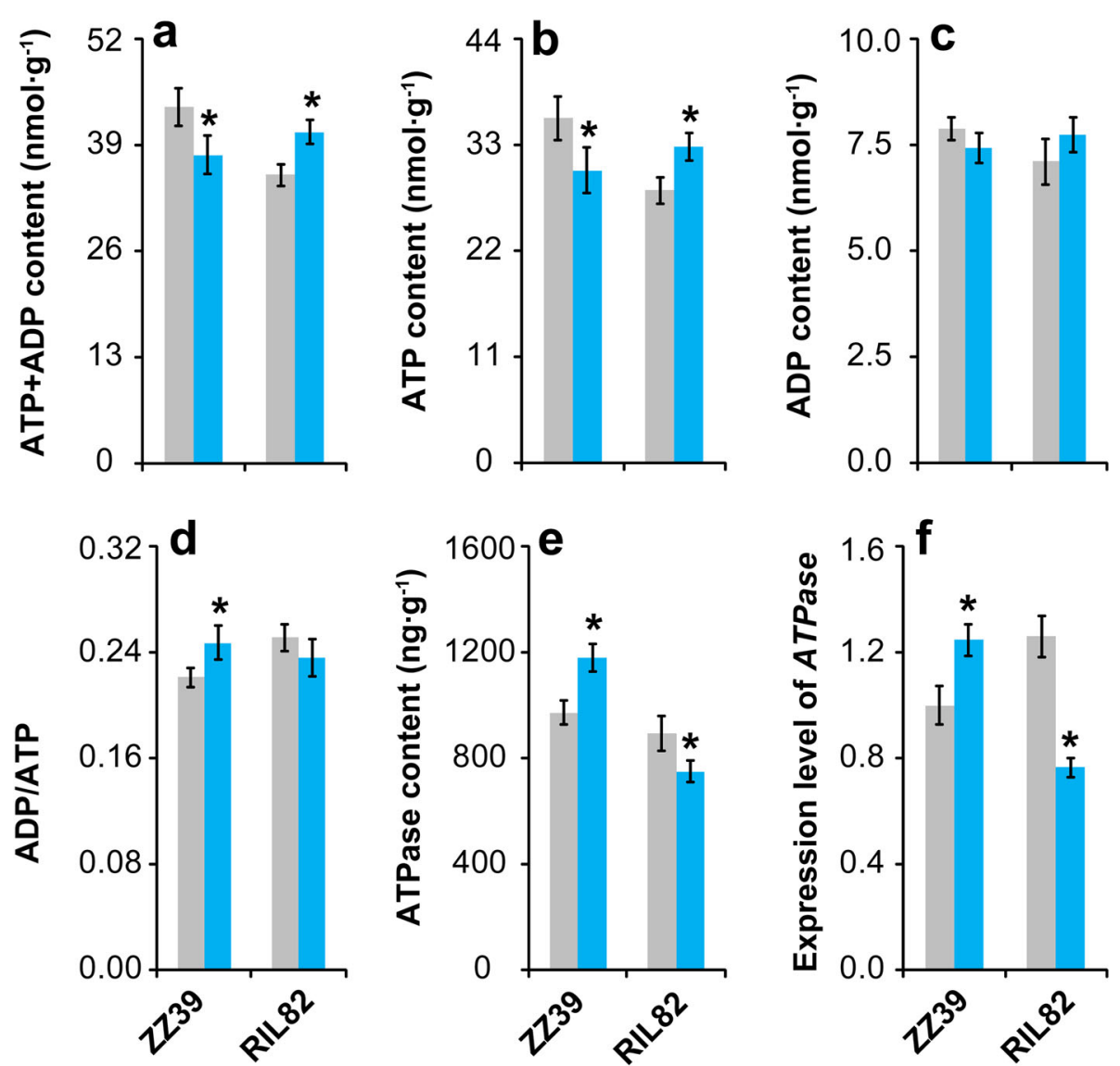

Fig. 5 Effect of cold stress on the ATP metabolism in rice leaves. a, ATP + ADP; $\mathbf{b}$, ATP; $\mathbf{c}$, ADP; $\mathbf{d}$, ADP/ATP; $\mathbf{e}$, ATPase; $\mathbf{f}$, expression level of ATPase. Vertical bars denote standard deviations $(n=3)$. A t-test was conducted to compare the difference between control and cold stress within a cultivar. ${ }^{*}$ denotes $P<0.05$ 

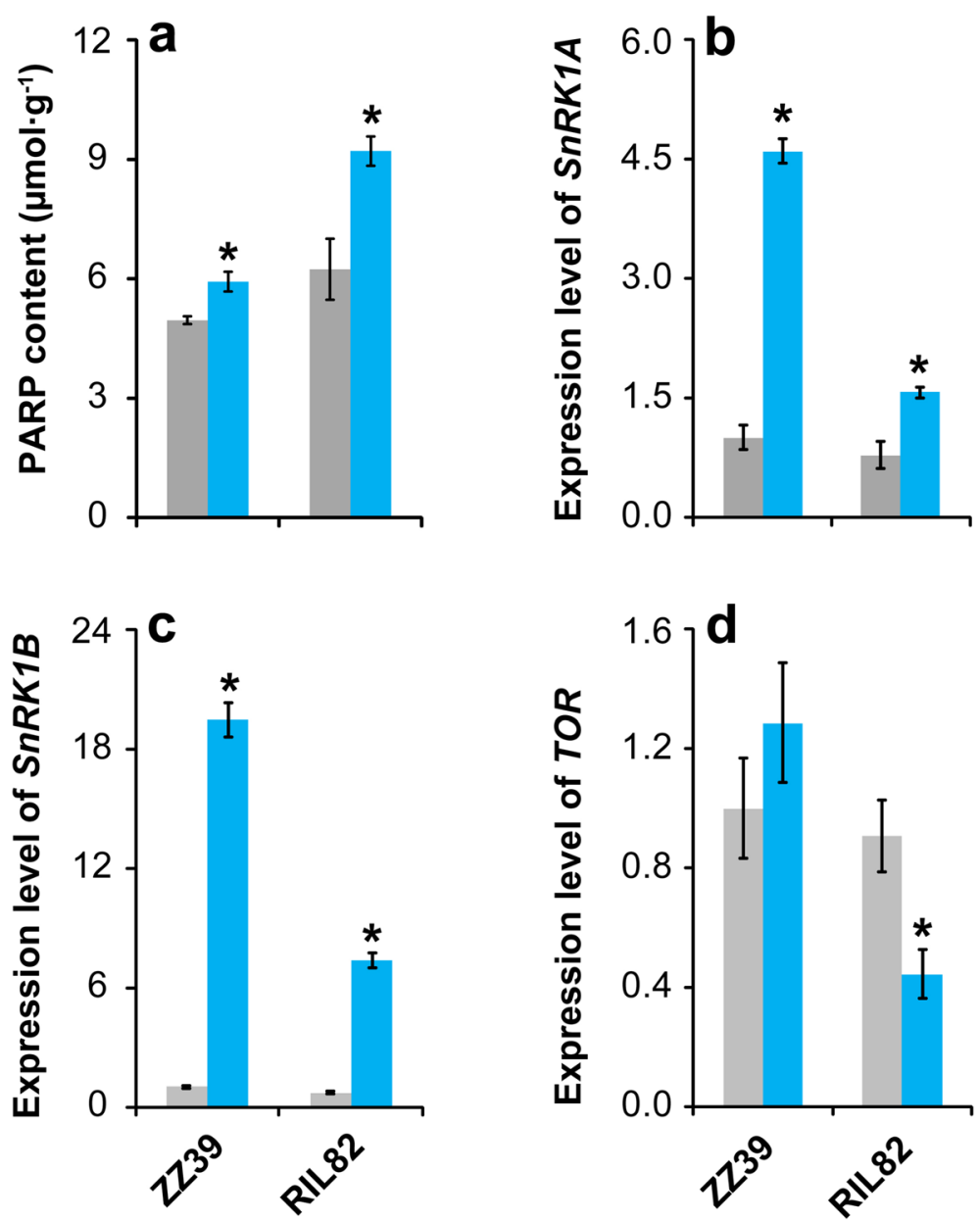

Fig. 6 Effects of cold stress on PARP content and expression levels of genes related to SnRK1 and TOR in rice leaves. PARP, Poly (ADP-ribose) polymerase; SnRK1, SNF1-related protein kinase; TOR, Target of rapamycin. Vertical bars denote standard deviations $(n=3)$. A $t$-test was conducted to compare the difference between control and cold stress within a cultivar. ${ }^{*}$ denotes $P<0.05$

The Role of Energy Status in Plants in GSH Accumulation under Cold Stress

According to above results, energy deficit was not the main limiting factor for the lower GSH accumulation in RIL82 plants caused by cold stress, because the ATP content in RIL82 plants increased significantly under cold stress, while it clearly decreased in ZZ39 plants. Under cold stress, the increases in expression levels of GSH1 and GSH2 in RIL82 plants were higher than those in ZZ39 plants. However, the increases in ATPase content and ATPase expression level of ZZ39 plants were significantly higher than those of RIL82 under cold stress. We inferred that inhibition of ATP hydrolysis by cold stress might be the main constraint factor for $\mathrm{GSH}$ accumulation in cold-sensitive genotype RIL82 (Fig. 7 and Fig. S1). Therefore, GSH and 3-ab were sprayed separately or together onto rice plants to confirm the hypothesis that energy utilization ability is related to the accumulation of GSH in plants under cold stress.
Effect of GSH, BSO or 3-Ab on Rice Plants under Cold Stress In response to cold stress, the REC of both genotypes increased significantly (Fig. 8A, a and b). However, GSH reversed this effect, since the REC in leaves of plants treated with GSH was significantly lower than that of $\mathrm{H}_{2} \mathrm{O}$ treatment under cold stress. Accordingly, rice plants treated with $\mathrm{BSO}$ had the highest REC among all treatments in both rice plants under cold stress. Similarly, MDA significantly increased in both rice plants under cold stress, among which GSHtreated plants had the lowest content, while BSO treatment had the highest value (Fig. 8A, c and d). Compared with the plants treated with $\mathrm{H}_{2} \mathrm{O}$, a remarkable reduction in REC and MDA was found in the plants of ZZ39 treated with 3-ab under cold stress (Fig. 8B). However, such results were not found in RIL82 plants, as no significant difference was showed between the treatments of $\mathrm{H}_{2} \mathrm{O}$ and 3-ab under cold stress. 


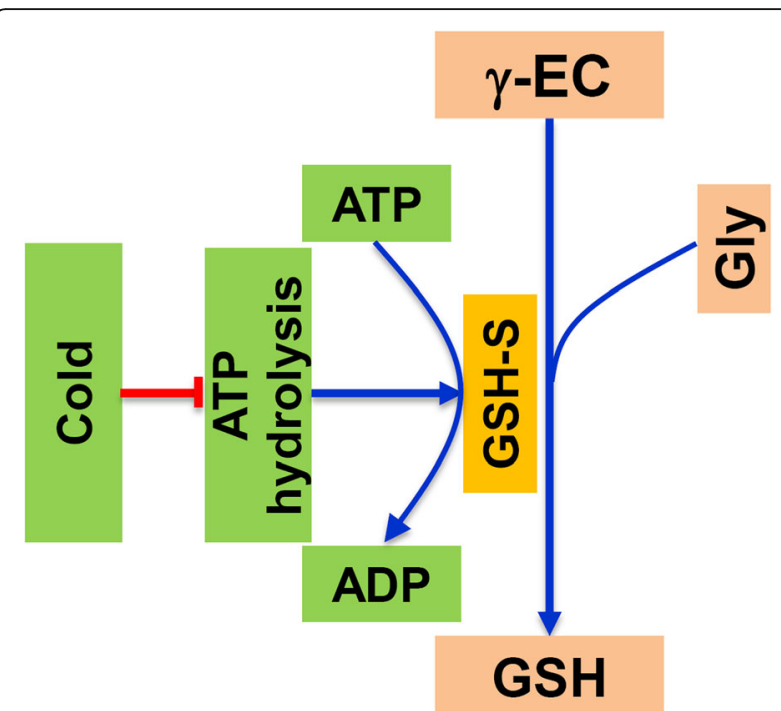

Fig. 7 Descriptive model of the mechanism of cold stress reducing GSH by inhibiting ATP hydrolysis in rice leaves. The $\gamma$-EC and Gly is converted into GSH by Glutathione synthetase (GSH-S) in plants. This pathway requires energy consumption (ATP). Under cold stress, ATP content significantly increases in the cold susceptible cultivar, indicating that it is not inhibited by stress. In contrast, cold stress inhibits the hydrolysis of ATP, resulting in low GSH accumulation, thereby reducing available energy. $Y$-EC, Y-glutamylcysteine; Gly, Glycine

\section{Effects of GSH and 3-Ab Combination on Rice Plants under Cold Stress}

The above results indicated that exogenous GSH enhanced cold tolerance in these two rice plants, while such result was only found in ZZ39 plants when treated with PARP inhibitor (3-ab). Thus, we wonder whether there is a synergistic effect between GSH and 3-ab in enhancing cold tolerance in plants. According to the photos, the leaves of ZZ39 treated with $\mathrm{H}_{2} \mathrm{O}$ or 3-ab wilted slightly under cold stress, while the plants treated with GSH or GSH + 3-ab maintained flat (Fig. 9a, b). In contrast, the leaves of RIL82 plants treated with $\mathrm{H}_{2} \mathrm{O}$ and 3-ab severely wilted under cold stress, whereas these effects were reversed by GSH or GSH + 3-ab, especially for the old leaves (Fig. S2).

Under cold stress, similar changing patterns of MDA and $\mathrm{H}_{2} \mathrm{O}_{2}$ were found in plants treated with GSH or 3ab alone (Fig. 9c-f). Additionally, the lowest MDA and $\mathrm{H}_{2} \mathrm{O}_{2}$ levels were showed in the plants treated with $\mathrm{GSH}+3-\mathrm{ab}$ under cold stress. Compared with 3-ab treatment, slight decreases in MDA and $\mathrm{H}_{2} \mathrm{O}_{2}$ levels were showed in ZZ39 plants treated with $\mathrm{GSH}+3-\mathrm{ab}$, while a remarkable reduction was observed in RIL82 plants. Regarding the GSH content, it clearly increased in plants treated with $\mathrm{GSH}$ or $\mathrm{GSH}+3-\mathrm{ab}$ treatments compared with $\mathrm{H}_{2} \mathrm{O}$ treatment in both rice plants in response to cold stress (Fig. 9g, h). Indeed, higher GSH content was found in both plants treated with 3-ab than those plants treated with $\mathrm{H}_{2} \mathrm{O}$, but significant difference was only found in ZZ39 plants.

Rice plants treated with GSH, 3-ab or $\mathrm{GSH}+3-\mathrm{ab}$ attained lower PARP content than $\mathrm{H}_{2} \mathrm{O}$ treatment in both rice plants under cold stress (Fig. 9i, j). However, significant difference was only found in the treatments of 3-ab or $\mathrm{GSH}+3-\mathrm{ab}$ compared with $\mathrm{H}_{2} \mathrm{O}$ under cold stress. As to the ATP, the highest levels were showed in the plants treated with 3-ab in both plants under cold stress, which was significantly higher than other treatments (Fig. 9k, l). Interestingly, the lowest value was observed in GSH treatment, but the difference was not significant compared with $\mathrm{H}_{2} \mathrm{O}$ treatment. Under cold stress, the highest content of ATPase were showed in the treatments of $\mathrm{GSH}$ and $\mathrm{GSH}+3 \mathrm{ab}$ in both rice plants, while the lowest content were found in plants treated with $\mathrm{H}_{2} \mathrm{O}$ and 3-ab (Fig. 9m, n). In ZZ39 plants, lower ATPase content was found in $\mathrm{H}_{2} \mathrm{O}$ treatment than 3-ab treatment under cold stress, while no significant differences between these two treatments were showed in RIL82 plants.

\section{Discussion}

The Function of GSH in Conferring Cold Tolerance in Rice Plants

The present results indicated that cold stress caused more damages to RIL82 than ZZ39 plants (Fig. 1), since excess $\mathrm{MDA}$ and $\mathrm{H}_{2} \mathrm{O}_{2}$ were showed in the former than latter (Fig. 2A). As well known, antioxidant enzymes including SOD, POD, CAT and APX can be induced by abiotic stress to alleviate the oxidant stress in plants (Ahmad et al. 2010; Fu et al. 2016; Zhang et al. 2016). Interestingly, APX was the only antioxidant responsible for maintaining ROS homeostasis in rice plants under cold stress (Fig. 2B). This finding was inconsistent with the results that these antioxidants always worked together to resist oxidant stress (Zhang et al. 2017; Gupta et al. 2018; Naeem et al. 2018; Islam et al. 2019). However, similar results were also presented in the research of Liu et al. (2018), who reported that 5-aminolevulinic acid conferred cold tolerance in plants via enhancing the APX, rather than the CAT, with a large increase in accumulation of GSH and ASA. In this study, remarkable increases were found in contents of GSH + GSSG, GSH and GSSG of ZZ39 compared with RIL82 under cold stress, while such effects were not found in GSH/ GSSG and GR (Fig. 3). This suggested that GSH might be the main factor resulting in different cold tolerance between these two rice plants. Importantly, exogenous GSH significantly enhanced cold tolerance in both rice plants, whereas this was impaired by its synthetic inhibitor BSO (Fig. 8A). 


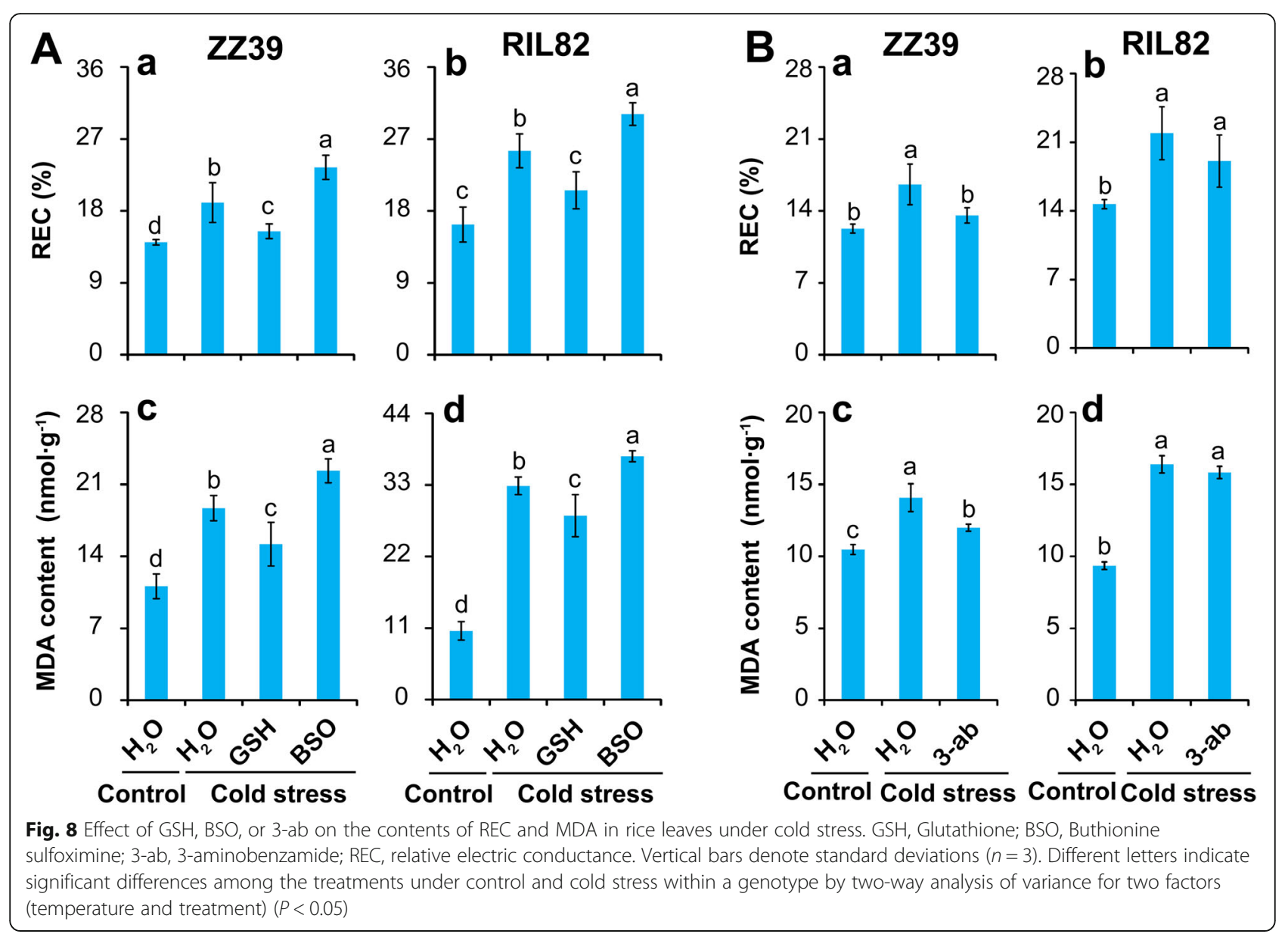

The Role of ATP Hydrolysis in GSH Synthesis in Rice Plants under Cold Stress

The GSH accumulation is determined by glutathione synthetase (GSH-S) and GR in plants, and the former are responsible for the GSH synthesis using the $\gamma$-EC and Gly while the latter reduces the GSSG to GSH (Rao and Reddy 2008; Noctor et al. 2012). According to the present results, the GSH-S rather than GR is responsible for GSH accumulation in plants under cold stress (Fig. 3). The genes of GSH1 and GSH2 encoding $\gamma$-ECS and GSH-S respectively are mainly responsible for the synthesis of GSH in plants (Cairns et al. 2006; Pasternak et al. 2008). However, higher increases in expression levels of GSH1 and GSH2 were showed in RIL82 than ZZ39 plants under cold stress (Fig. 3). These paradoxical results might be mainly ascribed to the energy status in plants under cold stress, since these two pathways is ATP dependent (Buwalda et al. 1990; Noctor et al. 1997; Ogawa et al. 2004).

Energy homeostasis is important for plants to survive in abiotic stress, which always result in energy shortage to inhibit the plants growth and development (De Block and Van Lijsebettens 2011; Xiong and Sheen 2015; Zhang et al. 2018b; Islam et al. 2019; Rodriguez et al.
2019). However, it was the energy ultilization ability rather than energy shortage that mainly contributed to the different cold tolerance between these two rice plants (Figs. 4 and 5). The ATPase content and its expression level increased significantly under cold stress in ZZ39 plants, while a large decrease was found in RIL82 plants (Fig. 4). This suggested that ATP hydrolysis in RIL82 plants were adversely inhibited by cold stress, and thus the lower GSH synthesis because of the higher unavailable ATP (Puhakainen et al. 1999; Mendoza et al. 2000; Deng et al. 2015; Muzi et al. 2016). This hypothesis was confirmed by the present results that the PARP inhibitor (3-ab) only enhanced the cold tolerance and GSH content in ZZ39 plants under cold stress (Fig. 8B and 9), though the ATP content increased significantly in both rice plants (Fig. 9k and $\mathrm{l}$ ).

It is puzzling that the ATP hydrolysis increased in RIL82 plants under cold stress in the present of exogenous GSH (Fig. 9n). This indicated that exogenous GSH could activate ATPase to provide energy for the GSH synthesis under cold stress. Similar results have not been documented previously that how GSH activating ATPase in plants under cold stress remains unclear. 


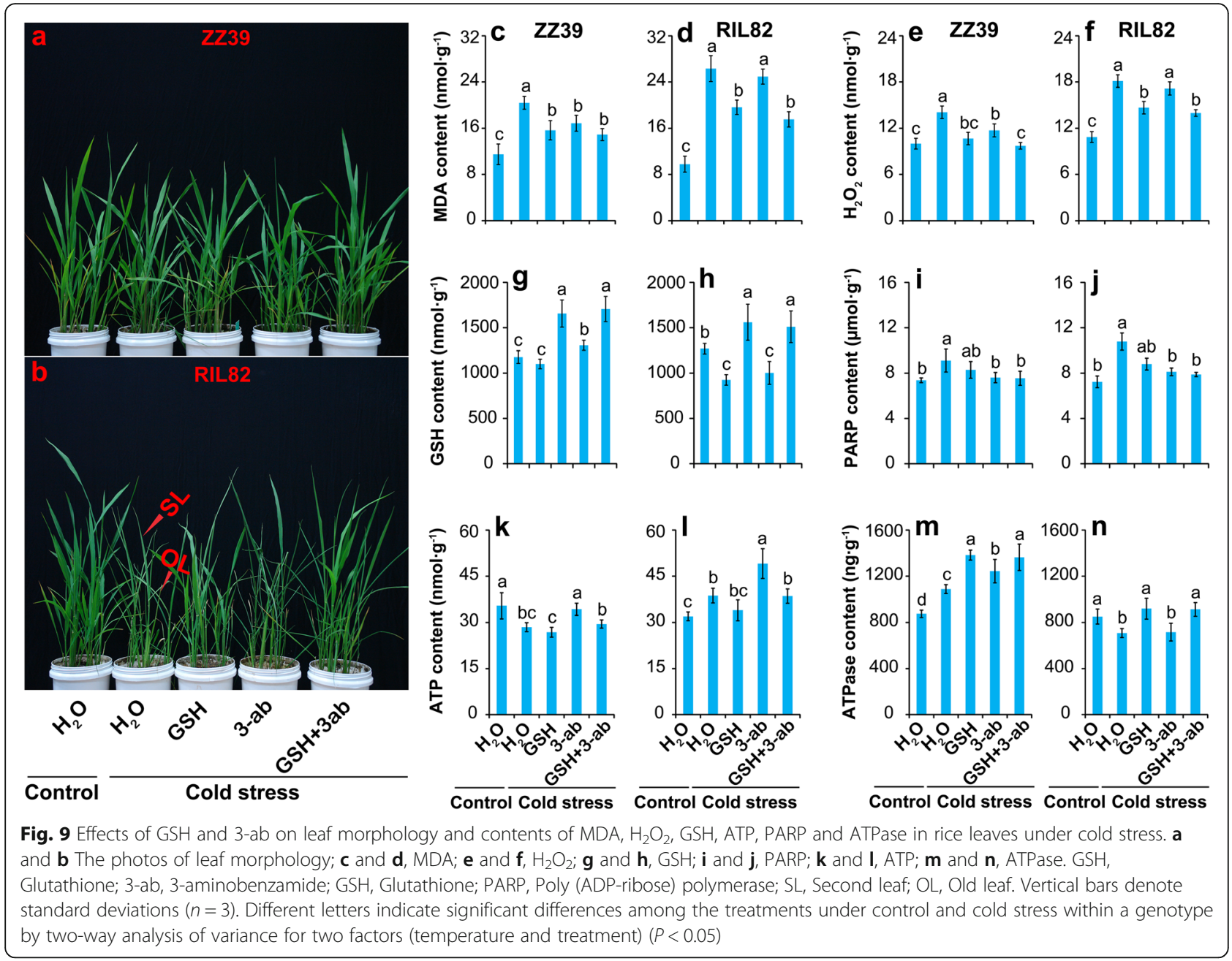

The Energy Allocation for Rice Plants to Survive in Cold Stress It has been reported that the ATP synthetic rates are adversely inhibited in abiotic stress conditions (Gibbs and Greenway 2003), where higher rates of glycolysis and activities of fermentative enzymes were observed in plants (Gibbs et al. 2000; Saika et al. 2006). In this case, the complementary responses could be used by the plants with low energy status to stabilize energy charge, including that ATP-regenerating pathways such as glycolysis become derepressed to maximize energy production and retard ATP-utilizing pathways to conserve ATP (Gibbs et al. 2000). In this study, more energy consumption was found in the ZZ39 plants than RIL82 under cold stress (Figs. 4 and 5). This strategy was not beneficial for plants to resist cold stress. However, there is a hierarchical down-regulation of ATP consumption during periods of ATP shortage (Atwell et al. 1982; Gibbs and Greenway 2003), in which the protein consumed the largest proportion of ATP synthesis (Edwards et al. 2012). This explained the remarkable decrease in ATP in ZZ39 plants, but higher increases in content of GSH and expression levels of heat shock proteins than RIL82 plants under cold stress. Thus, we inferred that the ZZ39 plants consumed more energy for the synthesis of GSH and heat shock proteins to resist cold stress, rather than the plant growth and development.

Heat shock protein is always accumulated to confer heat tolerance in plants under heat stress (Merret et al. 2017; Islam et al. 2019; Jiang et al. 2020; Li et al. 2020). It is worth noting that, similar results were also found in the rice plants under cold stress, in which higher increase in expression levels of HSP71.1 and HSP24.1 were found in the cold resistant plants than the cold susceptible one compared with their respective controls (Fig. 2C). This finding is consistent with the previous results that the accumulation of heat shock proteins is also found in plants under drought, salt, and oxidant stress (Kim et al. 2012; Jacob et al. 2017; Zhang et al. 2018c; Zandalinas et al. 2018). Actually, in addition to its protective effect under stress conditions, the heat shock protein also plays 
a role in plant development under normal growth conditions (Neta-Sharir et al. 2005).

SnRK1 and TOR which act in opposite ways in the regulation of metabolic-driven processes, play central roles in balancing energy requirements with supplies for plants to survive in unfavorable conditions (Baena-González and Hanson 2017; Crepin and Rolland 2019; Margalha et al. 2019). Without exception, notably higher increases in expression levels of SnRK1A and $S n R K 1 B$ were found in ZZ39 than RIL82 plants under cold stress (Fig. 6b, c), which was consistent with the previous results (Valledor et al. 2013; Lin et al. 2014; Yu et al. 2018). However, a large decrease in expression level of TOR was showed in RIL82, rather than ZZ39 plants under cold stress (Fig. 6d). Clearly, this changing pattern between SnRK1 and TOR don't follow the "yin-Yang" model (Rodriguez et al. 2019). It has been reported that the TOR can be activated to induce the synthesis of GSH and heat shock proteins and confer cold and drought tolerance in plants (Dobrenel et al. 2013; Xiong and Sheen 2015; Bakshi et al. 2017; Speiser et al. 2018; Rodriguez et al. 2019). This suggests that the antagonism between the SnRK1 and TOR may be ambiguous and the kinases may act in a different way under certain physiological circumstances (Rodriguez et al. 2019). The target genes of TOR and SnRK1 kinases only partially and not always antagonistically overlay under energy deficiency (Wu et al. 2019). Additionally, the TOR was reported to be activated by ATPase (Zoncu et al. 2011), which could explain the lower expression level of $T O R$ showed in RIL82 than ZZ39 under cold stress. Therefore, we inferred that the ATPase might function in the process of SnRK1 and TOR acting together to regulate the energy homeostasis in plants under cold stress.

\section{Conclusion}

Cold stress caused more damages to RIL82 than ZZ39 plants, since higher increases in REC, MDA and $\mathrm{H}_{2} \mathrm{O}_{2}$ were found in the former than the latter. Among the antioxidants including SOD, POD, CAT, APX, GSH, and GR, there were only APX and GSH involved in regulating cold tolerance between the two rice plants. The APX activity and GSH content increased significantly in ZZ39 plants under cold stress, while in RIL82 plants no obvious differences were showed between the control and cold stress. However, significantly higher increases in expression levels of GSH1 and GSH2 as well as contents of carbohydrates, $\operatorname{NAD}(\mathrm{H}), \operatorname{NADP}(\mathrm{H})$ and ATP were found in RIL82 under cold stress, rather than the ZZ39 plants. These findings indicated that lower GSH accumulation in RIL82 plants was not due to the energy deficit caused by cold stress. It's worth noting that, the ATPase content and its expression level increased obviously in ZZ39 plants under cold stress, while a remarkable decrease was found in RIL82 plants.
This suggested that the ATP hydrolysis by ATPase play a key role in GSH accumulation. Therefore, we inferred that the ATPase was the main factor responsible for determining cold tolerance between these two rice plants via regulating the GSH accumulation.

\section{Supplementary information}

Supplementary information accompanies this paper at https://doi.org/10. 1186/s12284-020-00383-7.

\begin{abstract}
Additional file 1: Table S1. Primer sequences used in quantitative Real-Time reverse transcription PCR. Figure S1. Descriptive model of relationships among the GSH accumulation, heat shock protein and energy homeostasis in plants under cold stress. The GSH plays a key role in reducing ROS by regulating the APX activity in plants, which can alleviate cold damage. During this process, the accumulation of GSH is determined by GSH-S and GR, the former consumes ATP, while the latter consumes $\mathrm{NADPH}$. The heat shock protein can be induced by ROS, which in turn reduce excess ROS in plants. Indeed, the accumulation of heat shock protein is a process of high energy consumption via consuming ATP. Thus, PARP which can be activated by ROS could inhibit the accumulation of heat shock proteins because it can consume $\mathrm{NAD}^{+}$and thereby reduce ATP under cold stress. $\gamma$-EC, Y-glutamylcysteine; Gly, Glycine; GSH, Glutathione; 3-ab, 3-aminobenzamide; GSH, Glutathione; PARP, Poly (ADP-ribose) polymerase. Figure S2. The morphology of the second and old leaves in RIL82 plants under cold stress. SL, Second leaf; OL, Old leaf.
\end{abstract}

\begin{abstract}
Abbreviations
3-ab: 3-aminobenzamide; APX: Ascorbate peroxidase; BSO: Buthionine sulfoximine; CAT: Catalase activity; DHAR: Dehydroascorbate reductase; Fv/ Fm: Maximum fluorescence quantum efficiency; CS: Cold stress; GR: Glutathione reductase; GSH: Glutathione; GSH-S: Glutathione synthetase; HSP: Heat shock protein; MDA: Malondialdehyde; MDHAR: Monodehydroascorbic acid reductase; NSC: Non-structural carbohydrates; PARP: Poly (ADP-Ribose) Polymerases; POD: Peroxidase; REC: Relative electrical conductance; ROS: Reactive oxygen species; SOD: Superoxide dismutase; Y (II): Actual fluorescence quantum efficiency; $Y$ ECS: $\gamma$-glutamylcysteine synthetase
\end{abstract}

\section{Acknowledgements}

Not applicable.

\section{Authors' Contributions}

Longxing Tao, Guanfu Fu conceived the original research plan and supervised the research work; Pinghui Yu, Ning Jiang, Guanfu Fu, Tingting Chen, Baohua Feng, Guangyan Li, Weimeng Fu Guangjie Zheng, Jiaying Ma, and Hubo Li performed research; Pinghui Yu, Ning Jiang, and Guanfu Fu analyzed the data and wrote the paper. All authors read and approved the final manuscript.

\section{Funding}

This work was funded by the National Food Science and Technology Project (Grant 2016YFD0300208), National Natural Science Foundation of China (Grant No. 31561143003 and 31671619), Zhejiang Provincial Natural Science Foundation, China (LQ18C130003; LY19C130006), The Central Public Interest Research Institute Special Fund in China (Grant No. 2017RG004-1), The National Rice Industry Technology System (CARS-1).

\section{Availability of Data and Materials}

The datasets supporting the conclusions of this article are included in the article (and its additional files).

Ethics Approval and Consent to Participate Not applicable. 


\section{Competing Interests}

The authors declare that they have no competing interests.

Received: 2 January 2020 Accepted: 23 March 2020

Published online: 09 April 2020

\section{References}

Aebi H (1974) Catalase. In: Bergmeyer HU (ed) Methods of enzymatic analysis. Academic Press, New York, pp 673-677

Ahmad P, Jaleel CA, Salem MA, Nabi G, Sharma S (2010) Roles of enzymatic and nonenzymatic antioxidants in plants during abiotic stress. Crit Rev Biotechnol 30:161-175

Aryal M, Kandel M (2017) Food security in South Asia and self-reliance in paddy. J Agric Environ 18:73-82

Asami P, Mundree S, Williams B (2018) Saving for a rainy day: control of energy needs in resurrection plants. Plant Sci 271:62-66

Atwell BJ, Waters I, Greenway H (1982) The effect of oxygen and turbulence on elongation of coleoptiles of submergence-tolerant and-intolerant rice cultivars. J Exp Bot 33:1030-1044

Baena-González E, Hanson J (2017) Shaping plant development through the SnRK1-TOR metabolic regulators. Curr Opin Plant Biol 35:152-157

Baena-González E, Sheen J (2008) Convergent energy and stress signaling. Trends Plant Sci 13:474-482

Bakshi A, Moin M, Kumar MU, Reddy ABM, Ren M, Datla R et al (2017) Ectopic expression of Arabidopsis target of Rapamycin (AtTOR) improves water-use efficiency and yield potential in rice. Sci Rep 7:42835

Banerjee A, Roychoudhury A (2019) Role of glutathione in plant abiotic stress tolerance. Reactive Oxygen, Nitrogen and Sulfur Species in Plants: Production, Metabolism, Signaling and Defense Mechanisms, pp 159-172. https://doi.org/10.1002/9781119468677.ch7

Belorgey D, Lanfranchi DA, Davioud-Charvet E (2013) 1,4-naphthoquinones and other NADPH-dependent glutathione reductase-catalyzed redox cyclers as antimalarial agents. Curr Pharm Des 19:2512-2528

Bonnecarrère V, Borsani O, Díaz P, Capdevielle F, Blanco P, Monza J (2011) Response to photoxidative stress induced by cold in japonica rice is genotype dependent. Plant Sci 180:726-732

Bowers MC (1994) Environmental effects of cold on plants. In: Wilkinson RE (ed) Plant-environment interactions. Marcel Dekker, New York, pp 391-411

Brennan T, Frenkel C (1977) Involvement of hydrogen peroxide in the regulation of senescence in pear. Plant Physiol 59:411-416

Buwalda F, Stulen I, De Kok LJ, Kuiper PJC (1990) Cysteine, Y-glutamyl-cysteine and glutathione contents of spinach leaves as affected by darkness and application of excess sulfur. II. Glutathione accumulation in detached leaves exposed to $\mathrm{H}_{2} \mathrm{~S}$ in the absence of light is stimulated by the supply of glycine to the petiole. Physiol Plant 80:196-204

Cairns NG, Pasternak M, Wachter A, Cobbett CS, Meyer AJ (2006) Maturation of Arabidopsis seeds is dependent on glutathione biosynthesis within the embryo. Plant Physiol 141:446-455

Chauhan BS, Jabran K, Mahajan G (eds) (2017) Rice production worldwide, vol 247. Sprinker International Publishing, Cham, Switzerland

Chen TT, Zhao X, Zhang CX, Yang YJ, Feng BH, Zhang XF et al (2017) Application of salicylic acid improves filling of inferior grains of rice during late maturity under mild cold stress. Crop Sci 57:2130-2142

Chen ZY, Wang YT, Pan XB, Xi ZM (2019) Amelioration of cold-induced oxidative stress by exogenous 24-epibrassinolide treatment in grapevine seedlings: toward regulating the ascorbate-glutathione cycle. Sci Hortic 244:379-387

Chinnusamy V, Zhu J, Zhu JK (2007) Cold stress regulation of gene expression in plants. Trends Plant Sci 12:444-451

Cong Dien D, Yamakawa T (2019) Phenotypic variation and selection for coldtolerant Rice (Oryza sativa L.) at germination and seedling stages. Agriculture 9:162

Crepin N, Rolland F (2019) SnRK1 activation, signaling, and networking for energy homeostasis. Curr Opin Plant Biol 51:29-36

Csiszár J, Horváth E, Bela K, GalléÁ (2016) Glutathione-related enzyme system: glutathione reductase (GR), glutathione transferases (GSTs) and glutathione peroxidases (GPXs). Cham, Switzerland: Springer International Publishing, p. $137-158$

Dahal K, Vanlerberghe GC (2017) Improved chloroplast energy balance during water deficit enhances plant growth: more crop per drop. J Exp Bot 69:1183-1197
De Block M, Van Lijsebettens M (2011) Energy efficiency and energy homeostasis as genetic and epigenetic components of plant performance and crop productivity. Curr Opin Plant Biol 14:275-282

Deng S, Sun J, Zhao R et al (2015) Populus euphratica APYRASE2 enhances cold tolerance by modulating vesicular trafficking and extracellular ATP in Arabidopsis plants. Plant Physiol 169:530-548

Dhindsa RS, Plumb-Dhindsa P, Thorpe TA (1981) Leaf senescence: correlated with increased levels of membrane permeability and lipid peroxidation, and decreased levels of superoxide dismutase and catalase. J Exp Bot 32:93-101

Dobrenel T, Marchive C, Azzopardi M, Clément G, Moreau M, Sormani R et al (2013) Sugar metabolism and the plant target of rapamycin kinase: a sweet operaTOR? Front Plant Sci 4:93

Dubois M, Gilles KA, Hamilton JK, Rebers PA, Smith F (1956) Colorimetric method for determination of sugars and related substances. Anal Chem 28:350-356

Edwards JM, Roberts TH, Atwell BJ (2012) Quantifying ATP turnover in anoxic coleoptiles of rice (Oryza sativa) demonstrates preferential allocation of energy to protein synthesis. J Exp Bot 63:4389-4402

Feng BH, Yang Y, Shi YF, Shen HC, Wang HM, Huang QN et al (2013) Characterization and genetic analysis of a novel Rice spotted-leaf mutant HM47 with broad-spectrum resistance to Xanthomonas oryzae pv. Oryzaeoryzae pv.Oryzae. J Integr Plant Biol 55:473-483

Fu GF, Feng BH, Zhang CX, Yang YJ, Yang XQ, Chen TT et al (2016) Heat stress is more damaging to superior spikelets than inferiors of rice (Oryza sativa L.) due to their different organ temperatures. Frontiers in. Plant Sci 7:1637

Galiba G, Kerepesi I, Vagujfalvi A, Kocsy G, Cattivelli L, Dubcovsky J et al (2001) Mapping of genes involved in glutathione, carbohydrate and COR14b cold induced protein accumulation during cold hardening in wheat. Euphytica 119:173-177

Ghadirnezhad R, Fallah A (2014) Temperature effect on yield and yield components of different rice cultivars in flowering stage. Int J Agronomy 2014:1-4

Giannopolitis CN, Ries SK (1977) Superoxide dismutases: I. occurrence in higher plants. Plant Physiol 59:309-314

Gibbs J, Greenway H (2003) Mechanisms of anoxia tolerance in plants. I. Growth, survival and anaerobic catabolism. Funct Plant Biol 30:1-47

Gibbs J, Morrell S, Valdez A, Setter TL, Greenway H (2000) Regulation of alcoholic fermentation in coleoptiles of two rice cultivars differing in tolerance to anoxia. J Exp Bot 51:785-796

Gupta DK, Palma JM, Corpas FJ (eds) (2018) Antioxidants and antioxidant enzymes in higher plants. Springer International Publishing, USA

Halliwell B, Foyer CH (1978) Properties and physiological function of a glutathione reductase purified from spinach leaves by affinity chromatography. Planta 139:9-17

Han QH, Huang B, Ding CB, Zhang ZW, Chen YE, Hu C et al (2017) Effects of melatonin on anti-oxidative systems and photosystem II in cold-stressed rice seedlings. Front Plant Sci 8:785. https://doi.org/10.3389/fpls.2017.00785

Hausladen A, Alscher RG (2017) Glutathione. In: Antioxidants in higher plants. p, pp 1-30

Islam MR, Feng BH, Chen TT, Fu WM, Zhang CX, Tao LX et al (2019) Abscisic acid prevents pollen abortion under high-temperature stress by mediating sugar metabolism in rice spikelets. Physiol Plant 165:644-663

Jacob P, Hirt H, Bendahmane A (2017) The heat-shock protein/chaperone network and multiple stress resistance. Plant Biotechnol J 15:405-414

Jiang N, Yu PH, Fu WM, Li GY, Feng BH, Chen TT et al (2020) Acid invertase confers heat tolerance in rice plants by maintaining energy homoeostasis of spikelets. Plant Cell Environ. https://doi.org/10.1111/pce.13733

Jin P, Zhang Y, Shan T, Huang Y, Xu J, Zheng Y (2015) Low-temperature conditioning alleviates chilling injury in loquat fruit and regulates glycine betaine content and energy status. J Agric Food Chem 63:3654-3659

Kazemi-Shahandashti SS, Maali-Amiri R (2018) Global insights of protein responses to cold stress in plants: signaling, defence, and degradation. J Plant Physiol 226:123-135

Keppler B, Song J, Nyman J, Voigt C, Bent A (2018) 3-aminobenzamide blocks MAMP-induced callose deposition independently of its poly (ADPribosyl) ation inhibiting activity. Front Plant Sci 9:1907

Kim KH, Alam I, Kim YG, Sharmin SA, Lee KW, Lee SH et al (2012) Overexpression of a chloroplast-localized small heat shock protein OsHSP26 confers enhanced tolerance against oxidative and heat stresses in tall fescue. Biotechnol Lett 34:371-377

Kim YS, An C, Park S, Gilmour SJ, Wang L, Renna L et al (2017) CAMTA-mediated regulation of salicylic acid immunity pathway genes in Arabidopsis exposed to low temperature and pathogen infection. Plant Cell 29:2465-2477 
Kocsy G, Szalai G, Vágúffalvi A, Stéhli L, Orosz G, Galiba G (2000) Genetic study of glutathione accumulation during cold hardening in wheat. Planta 210:295-301

Lang V, Mantyla E, Welin B, Sundberg B, Palva ET (1994) Alterations in water status, endogenous abscisic acid content, and expression of rab18 gene during the development of freezing tolerance in Arabidopsis thaliana. Plant Physiol 104:1341-1349

Li GY, Zhang CX, Zhang GH, Fu WM, Feng BH, Chen TT et al (2020) Abscisic acid negatively modulates heat tolerance in rolled leaf rice by increasing leaf temperature and regulating energy homeostasis. Rice. https://doi.org/10. 1186/s12284-020-00379-3

Li TG, Visperas RM, Vergara BS (1981) Correlation of cold tolerance at different growth stages in rice. Acta Bot Sin 23:203-207

Lin CR, Lee KW, Chen CY, Hong YF, Chen JL, Lu CA et al (2014) A-interacting negative regulators modulate the nutrient starvation signaling sensor in source-sink communication in cereal seedlings under abiotic stress. Plant Cell 26:808-827

Liu C, Schläppi MR, Mao B, Wang W, Wang A, Chu C (2019) The bZIP73 transcription factor controls rice cold tolerance at the reproductive stage. Plant Biotechnol J 17:1834-1849

Liu T, Hu X, Zhang J, Zhang J, Du Q, Li J (2018) $\mathrm{H}_{2} \mathrm{O}_{2}$ mediates ALA-induced glutathione and ascorbate accumulation in the perception and resistance to oxidative stress in Solanum lycopersicum at low temperatures. BMC Plant Biol 18:34

Maehly PC, Chance M (1954) The assay of catalase and peroxidases. In: Gluck D (ed) Methods of biochemical analysis. Interscience Publishers, New York, pp $357-424$

Margalha L, Confraria A, Baena-González E (2019) SnRK1 and TOR: modulating growth-defense trade-offs in plant stress responses. J Exp Bot 70:2261-2274

Matsumura H, Miyachi S (1980) Cycling assay for nicotinamide adenine dinucleotides. In methods in enzymology. Academic Press 69:465-470

McDonald CK (2002) Germination response to temperature in tropical and subtropical pasture legumes. 2. Alternating temperature. Aust J Exp Agric 42: $421-429$

Meister A (1988) Glutathione metabolism and its selective modification. J Biol Chem 263:17205-17208

Mendoza JA, Dulin P, Warren T (2000) The lower hydrolysis of ATP by the stress protein GroEL is a major factor responsible for the diminished chaperonin activity at low temperature. Cryobiology 41:319-323

Merret R, Carpentier MC, Favory JJ, Picart C, Descombin J, Bousquet-Antonelli C (2017) Heat shock protein HSP101 affects the release of ribosomal protein mRNAs for recovery after heat shock. Plant Physiol 174:1216-1225

Mullineaux PM, Rausch T (2005) Glutathione, photosynthesis and the redox regulation of stress-responsive gene expression. Photosynth Res 86:459-474

Muzi C, Camoni L, Visconti S, Aducci P (2016) Cold stress affects H+ATPase and phospholipase D activity in Arabidopsis. Plant Physiol Biochem 108: 328-336

Naeem A, Zia-ur-Rehman M, Akhtar T, Zia MH, Aslam M (2018) Silicon nutrition lowers cadmium content of wheat cultivars by regulating transpiration rate and activity of antioxidant enzymes. Environ Pollut 242:126-135

Neta-Sharir I, Isaacson T, Lurie S, Weiss D (2005) Dual role for tomato heat shock protein 21: protecting photosystem II from oxidative stress and promoting color changes during fruit maturation. Plant Cell 17:1829-1838

Noctor G, Arisi ACM, Jouanin L, Kunert KJ, Rennenberg H, Foyer CH (1998) Glutathione: biosynthesis, metabolism and relationship to stress tolerance explored in transformed plants. J Exp Bot 49:623-647

Noctor G, Arisi ACM, Jouanin L, Valadier MH, Roux Y, Foyer CH (1997) The role of glycine in determining the rate of glutathione synthesis in poplar. Possible implications for glutathione production during stress. Physiol Plant 100:255-263

Noctor G, Foyer CH (1998) Ascorbate and glutathione: keeping active oxygen under control. Annu Rev Plant Biol 49:249-279

Noctor G, Mhamdi A, Chaouch S, Han YI, Neukermans J, Marquez-Garcia B et al (2012) Glutathione in plants: an integrated overview. Plant Cell Environ 35: 454-484

Noctor G, Mhamdi A, Foyer CH (2016) Oxidative stress and antioxidative systems: recipes for successful data collection and interpretation. Plant Cell Environ 39:1140-1160

Ogawa Kl, Hatano-Iwasaki A, Yanagida M, Iwabuchi M (2004) Level of glutathione is regulated by ATP-dependent ligation of glutamate and cysteine through photosynthesis in Arabidopsis thaliana: mechanism of strong interaction of light intensity with flowering. Plant Cell Physiol 45:1-8
O'Kane D, Gill V, Boyd P, Burdon R (1996) Chilling, oxidative stress and antioxidant responses in Arabidopsis thaliana callus. Planta 198:371-377

Pasternak M, Lim B, Wirtz M, Hell R, Cobbett CS, Meyer AJ (2008) Restricting glutathione biosynthesis to the cytosol is sufficient for normal plant development. Plant J 53:999-1012

Puhakainen T, Pihakaski-Maunsbach K, Widell S, Sommarin M (1999) Cold acclimation enhances the activity of plasma membrane $\mathrm{Ca}_{2}{ }^{+}$ATPase in winter rye leaves. Plant Physiol Biochem 37:231-239

Rahaman MM, Shehab MK (2019) Water consumption, land use and production patterns of rice, wheat and potato in South Asia during 1988-2012. Sustainable Water Resources Manag 5:1677-1694

Rao AC, Reddy AR (2008) Glutathione reductase: a putative redox regulatory system in plant cells. In: Khan NA, Singh S, Umar S (eds) Sulfur assimilation and abiotic stresses in plants. Springer, Berlin, pp 111-147

Rennenberg H (1980) Glutathione metabolism and possible biological roles in higher plants. Phytochemistry 21:2771-2781

Rodriguez M, Parola R, Andreola S, Pereyra C, Martínez-Noël G (2019) TOR and SnRK1 signaling pathways in plant response to abiotic stresses: do they always act according to the"yin-yang" model? Plant Sci 288:110220

Rozen S, Skaletsky H (2000) Primer3 on the WWW for general users and for biologist programmers. In: Bioinformatics methods and protocols. Humana Press, Totowa, NJ, pp 365-386

Saika H, Matsumura H, Takano T, Tsutsumi N, Nakazono M (2006) A point mutation of Adh1 gene is involved in the repression of coleoptile elongation under submergence in rice. Breed Sci 56:69-74

Sanghera GS, Wani SH, Hussain W, Singh NB (2011) Engineering cold stress tolerance in crop plants. Curr Genom 12:30

Sartory DP, Grobbelaar JU (1984) Extraction of chlorophyll a from freshwater phytoplankton for spectrophotometric analysis. Hydrobiologia 114:177-187

Seck PA, Diagne A, Mohanty S, Wopereis MC (2012) Crops that feed the world 7: Rice. Food Security 4:7-24

Shi Y, Ding Y, Yang S (2018) Molecular regulation of CBF signaling in cold acclimation. Trends Plant Sci 23:623-637

Speiser A, Silbermann M, Dong Y, Haberland S, Uslu W, Wang SS et al (2018) Sulfur partitioning between glutathione and protein synthesis determines plant growth. Plant Physiol 177:927-937

Su CF, Wang YC, Hsieh TH, Lu CA, Tseng TH, Yu SM (2010) A novel MYBS3dependent pathway confers cold tolerance in rice. Plant Physiol 153:145-158

Sun W, Huang Y (2011) Global warming over the period 1961-2008 did not increase high-temperature stress but did reduce low-temperature stress in irrigated rice across China. Agric For Meteorol 151:1193-1201

Tausz M, Šircelj H, Grill D (2004) The glutathione system as a stress marker in plant ecophysiology: is a stress-response concept valid? J Exp Bot 55: 1955-1962

Thakur P, Kumar S, Malik JA, Berger JD, Nayyar H (2010) Cold stress effects on reproductive development in grain crops: an overview. Environ Exp Bot 67: 429-443

Thomashow MF (2010) Molecular basis of plant cold acclimation: insights gained from studying the CBF cold response pathway. Plant Physiol 154:571-577

Uphoff N, Thakur AK (2019) An Agroecological strategy for adapting to climate change: the system of Rice intensification (SRI). In: Sarkar A, Sensarma S, van Loon G (eds) Sustainable Solutions for Food Security. Springer, Cham, pp 229-254

Valledor L, Furuhashi T, Hanak AM, Weckwerth W (2013) Systemic cold stress adaptation of Chlamydomonas reinhardtii. Mol Cell Proteomics 12:2032-2047

Wang P, Zhang Z, Chen Y, Wei X, Feng B, Tao F (2016) How much yield loss has been caused by extreme temperature stress to the irrigated rice production in China? Clim Chang 134:635-650

Wang R, Li X, Tan M, Xin L, Wang X, Wang Y et al (2019) Inter-provincial differences in rice multi-cropping changes in main double-cropping rice area in China: evidence from provinces and households. Chin Geogr Sci 29:127-138

Wu L, Wu J, Liu Y, Gong X, Xu J, Lin D et al (2016) The rice pentatricopeptide repeat gene TCD10 is needed for chloroplast development under cold stress. Rice 9:1-1367

Wu Y, Shi L, Li L, Fu L, Liu Y, Xiong Y et al (2019) Integration of nutrient, energy, light and hormone signalling via TOR in plants. J Exp Bot 70:2227-2238

Xiong J, Zhang L, Fu G, Yang Y, Zhu C, Tao L (2012) Drought-induced proline accumulation is uninvolved with increased nitric oxide, which alleviates drought stress by decreasing transpiration in rice. J Plant Res 125:155-164 
Xiong Y, Sheen J (2015) Novel links in the plant TOR kinase signaling network. Curr Opin Plant Biol 28:83-91

Xu P, Cai W (2014) RAN1 is involved in plant cold resistance and development in rice (Oryza sativa). J Exp Bot 65:3277-3287

Yadav SK (2010) Cold stress tolerance mechanisms in plants. A review. Agronomy Sust Dev 30:515-527

Ye C, Fukai S, Godwin I, Reinke R, Snell P, Schiller J et al (2009) Cold tolerance in rice varieties at different growth stages. Crop Pasture Sci 60:328-338

Yoshida S (1981) Fundamentals of rice crop science. International Rice Research Institute, Manila, p 269

Yu C, Song L, Song J, Ouyang B, Guo L, Shang L et al (2018) ShCIGT, a Trihelix family gene, mediates cold and drought tolerance by interacting with in tomato. Plant Sci 270:140-149

Yu Y, Huang Y, Zhang W (2012) Changes in rice yields in China since 1980 associated with cultivar improvement, climate and crop management. Field Crop Res 136:65-75

Zandalinas SI, Mittler R, Balfagón D, Arbona V, Gómez-Cadenas A (2018) Plant adaptations to the combination of drought and high temperatures. Physiol Plant 162:2-12

Zhang CX, Feng BH, Chen TT, Fu WM, Li HB, Li GY et al (2018a) Heat stressreduced kernel weight in rice at anthesis is associated with impaired sourcesink relationship and sugars allocation. Environ Exp Bot 155:718-733

Zhang CX, Fu GF, Yang XQ, Yang YJ, Zhao X, Chen TT et al (2016) Heat stress effects are stronger on spikelets than on flag leaves in rice due to differences in dissipation capacity. J Agronomy Crop Sci 202:394-408

Zhang CX, Li GY, Chen TT, Feng BH, Fu WM, Yan JX et al (2018b) Heat stress induces spikelet sterility in rice at anthesis through inhibition of pollen tube elongation interfering with auxin homeostasis in pollinated pistils. Rice 11:1-12

Zhang L, Hu W, Gao Y, Pan H, Zhang Q (2018c) A cytosolic class II small heat shock protein, PfHSP17.2, confers resistance to heat, cold, and salt stresses in transgenic Arabidopsis. Genet Mol Biol 41:649-660

Zhang YP, Xu S, Yang SJ, Chen YY (2017) Melatonin alleviates cold-induced oxidative damage by regulation of ascorbate-glutathione and proline metabolism in melon seedlings (Cucumis melo L.). J Hortic Sci Biotechnol 92: 3313-3324

Zhao JL, Zhang SH, Yang TF, Zeng ZC, Huang ZH, Liu Q et al (2015) Global transcriptional profiling of a cold-tolerant rice variety under moderate cold stress reveals different cold stress response mechanisms. Physiol Plant 154: 381-394

Zoncu R, Bar-Peled L, Efeyan A, Wang S, Sancak Y, Sabatini DM (2011) mTORC1 senses lysosomal amino acids through an inside-out mechanism that requires the vacuolar $\mathrm{H}^{+}$-ATPase. Science 334:678-683

\section{Publisher's Note}

Springer Nature remains neutral with regard to jurisdictional claims in published maps and institutional affiliations.

\section{Submit your manuscript to a SpringerOpen ${ }^{\circ}$ journal and benefit from:}

- Convenient online submission

- Rigorous peer review

- Open access: articles freely available online

High visibility within the field

- Retaining the copyright to your article

Submit your next manuscript at $\boldsymbol{\nabla}$ springeropen.com 